\title{
Matrix metalloproteinases in early diabetic retinopathy and their role in alteration of the blood-retinal barrier
}

\author{
Stephen J Giebel ${ }^{1}$, Gina Menicucci ${ }^{1}$, Paul G McGuire ${ }^{1}$ and Arup Das ${ }^{2,3}$ \\ ${ }^{1}$ Department of Cell Biology and Physiology, University of New Mexico Health Sciences Center, Albuquerque, \\ NM, USA; ${ }^{2}$ Department of Surgery, Division of Ophthalmology, University of New Mexico Health Sciences \\ Center, Albuquerque, NM, USA and ${ }^{3}$ New Mexico VA Health Care System, Albuquerque, NM, USA
}

\begin{abstract}
One of the early features of diabetic retinopathy is the alteration of the blood-retinal barrier (BRB), which may involve the breakdown of endothelial cell tight junctions. The aim of this study was to examine the expression of extracellular proteinases in an animal model of early diabetic retinopathy and to determine their role in the alteration of the BRB. Matrix metalloproteinase (MMP) expression was studied in the retinas of rats with 12 weeks of diabetes. The role of MMPs in regulating tight junction function was investigated in retinal endothelial and pigment epithelial cells by measuring transepithelial electrical resistance (TER). The retinas of diabetic animals demonstrated elevated levels of MMP-2, MMP-9 and MMP-14 messenger RNA. A significant increase in the production of MMP-9 was seen when cells were exposed to high glucose conditions. Both cell types treated with purified MMP-2 or MMP-9 were found to have alterations of tight junction function as shown by decreased TER. Western blot analysis of cell extracts treated with MMP-2 or MMP-9, revealed specific degradation of the tight junction protein, occludin. Results suggest that elevated expression of MMPs in the retina may facilitate an increase in vascular permeability by a mechanism involving proteolytic degradation of the tight junction protein occludin followed by disruption of the overall tight junction complex.
\end{abstract}

Laboratory Investigation (2005) 85, 597-607, advance online publication, 14 February 2005; doi:10.1038/labinvest.3700251

Keywords: blood-retinal barrier; proteinases; tight junction; occludin; diabetic retinopathy

Breakdown of the blood-retinal barrier (BRB) is an early feature of diabetic retinopathy and results in vascular leakage and the development of retinal edema. ${ }^{1}$ Vascular permeability in the retina is partially regulated by the structural components of the BRB, the integrity of which is essential in maintaining normal visual function. The BRB forms a selective partition between the circulatory system and the neuronal and glial components of the retina. This partition is not absolute and allows some normal level of exchange between the retinal tissue and the circulation. The BRB consists of two anatomical entities: the inner BRB, which is formed by junctions between endothelial cells of the retinal capillaries, and the outer BRB, which is composed of tight junctions between retinal pigment epithelial cells. ${ }^{2}$ Clinical evidence from fluorescein angiogra-

Correspondence: Dr A Das, MD, PhD, Department of Surgery, University of New Mexico School of Medicine, 2211 Lomas Blvd, NE ACC-2, Albuquerque, NM 87131, USA.

E-mail: adas@unm.edu

Received 22 September 2004; revised and accepted 6 January 2005; published online 14 February 2005 phy in patients with diabetic retinopathy indicates that the inner BRB is the primary site of vascular leakage leading to macular edema.

Tight junction proteins are an integral structural component of the BRB. The principal proteins found in endothelial tight junctions are occludin and the claudin $-5{ }^{3}$ Both are transmembrane proteins that are linked to the actin cytoskeleton via interaction with the cytosolic proteins zona occludin-1 (ZO-1) and zona occludin-2 (ZO-2). Occludin is a $62-64 \mathrm{kDa}$ transmembrane protein with distinct extracellular and intracellular domains. Occludin by itself is not required for the formation of a functional tight junction. However, evidence suggests that occludin may have a role in the organization and stabilization of the tight junction complex and may coordinate the activity of the tight junction with the cytoskeleton. ${ }^{4}$ Claudins are another major component of the tight junction with important functions in both the structural organization and function of the junctions. Claudins are a family of proteins that are structurally similar to occludin in that they contain two extracellular domains as well as smaller intracellular carboxy- and amino-terminal domains. ${ }^{4,5}$ 
Two groups of extracellular proteinases that have been shown to play a role in the retinal neovascularization seen in the later stages of diabetic retinopathy, are the matrix metalloproteinases (MMPs) and the serine proteinase, urokinase plasminogen activator (uPA). MMPs are a class of approximately 25 known proteinases that function to degrade at least one component of the extracellular matrix in addition to other substrates. Urokinase is a serine proteinase that binds to the urokinase plasminogen activator receptor (UPAR) on the cell surface, and converts plasminogen to the broad-spectrum proteinase plasmin. Plasmin in turn degrades components of the matrix and can be involved in the activation of the latent MMPs. We have shown previously that the gelatinases, MMP-2, MMP-9 and uPA are increased in the epiretinal neovascular membranes of patients with proliferative diabetic retinopathy, ${ }^{6}$ as well as in retinas in an animal model of retinal neovascularization. ${ }^{7} \mathrm{MMP}-2$ and MMP-9 have also been shown to have significantly increased levels of activation in vitreous samples from individuals with proliferative diabetic retinopathy. ${ }^{8}$ Whether these extracellular proteinases play a role in early diabetic retinopathy and alteration of the BRB is unclear.

The aims of the present study were to examine the expression of MMPs in the rat retina during the early stages of diabetes and to correlate this to changes in vascular permeability. To determine if these enzymes play a role in the BRB alteration, additional studies looked at the effect of these enzymes on the breakdown or disruption of the tight junction barrier in isolated retinal pigment epithelial and microvascular endothelial cells.

\section{Research design and methods}

\section{Diabetic Animal Model}

Sprague-Dawley rats, 8 weeks old, weighing approximately $200 \mathrm{~g}$ were injected with a single intraperitoneal injection of streptozotocin $(60 \mathrm{mg} /$ $\mathrm{kg}$ ) in $10 \mathrm{mM}$ citrate buffer, $\mathrm{pH}$ 4.5. Control nondiabetic rats received injections of an equal volume of citrate buffer only. Diabetic rats were treated with $0.2 \mathrm{U}$ of NPH insulin, given no more than twice a week, to prevent weight loss and increase long-term survival. Body weight of all animals was measured 3-4 times a week and blood glucose measured every 7-10 days. Only animals with plasma glucose concentrations greater than $250 \mathrm{mg} / \mathrm{dl}, 24-48 \mathrm{~h}$ after streptozotocin injection were considered diabetic and included in the study. Total glycated hemoglobin $(\mathrm{GHb})$ was measured in each animal prior to killing using a commercially available assay kit (Perkin-Elmer Life Sciences, Norton, OH, USA). The animals were used for studies at 12 weeks of diabetes. Animals were treated in accordance with the Association for Research in Vision and Ophthal- mology (ARVO) Statement for the Use of Animals in Ophthalmic and Vision Resarch.

\section{Quantitative Assessment of BRB Permeability}

Vascular permeability in the retina was measured at 12 weeks of diabetes using an Evans blue quantitation technique. ${ }^{9}$ Rats were anesthetized with ketamine $(120 \mathrm{mg} / \mathrm{kg})$ and acepromazine $(1 \mathrm{mg} / \mathrm{kg})$. The left femoral artery and vein were exposed and cannulated using a 0.28 -mm diameter tubing (Scientific Commodities Inc., Lake Havasu City, AZ, USA) filled with heparinized normal saline $(200 \mathrm{U} / \mathrm{ml}$ NS). Evans blue $(45 \mathrm{mg} / \mathrm{kg})$ was injected into the femoral vein and, $2 \mathrm{~h}$ later, one eye was removed and dissected to obtain the retina for PCR analysis. The animal was subsequently perfused via the left ventricle with approximately $60 \mathrm{ml}$ citrate buffered paraformaldehyde $(1 \% \mathrm{wt} / \mathrm{vol})$ at $37^{\circ} \mathrm{C}$ over a $2 \mathrm{~min}$ interval to clear Evans blue from the circulation. The retina from the remaining eye was collected, dried for $2 \mathrm{~h}$ and weighed. The Evans blue dye was extracted by incubating each retina in $120 \mu \mathrm{l}$ of formamide for $18 \mathrm{~h}$ at $70^{\circ} \mathrm{C}$. The extract was centrifuged at $14000 \mathrm{~g}$ for $12 \mathrm{~min}$ at $25^{\circ} \mathrm{C}$ with a $30000 \mathrm{MW}$ filter (Millipore, Bedford, MA, USA). The absorbance of $80 \mu \mathrm{l}$ of the supernatant was measured by spectrophotometry. To determine the time-averaged Evans blue plasma concentration, $0.2 \mathrm{ml}$ of blood was withdrawn from the femoral artery 2 min after Evans blue injection. At 15-min intervals, $0.1 \mathrm{ml}$ of blood was withdrawn concluding with a $0.2 \mathrm{ml}$ sample of blood at the 2 -h mark. The blood samples were centrifuged at 12000 r.p.m. for $30 \mathrm{~min}$ and the plasma diluted $1 / 10000$ in formamide. Absorbance was measured by spectrophotometry at 620 and $740 \mathrm{~nm}$, the absorbance maximum and minimum, respectively, of Evans blue in formamide. The concentration of dye in the plasma was calculated from a standard curve of Evans blue in formamide. The BRB permeability was calculated as follows:

[Evans blue $(\mu \mathrm{g}) /$ retina dry weight $(\mathrm{g})] /$

[Time - averagedEvans blue concentration $(\mu \mathrm{g}) /$

plasma $(\mu \mathrm{l}) \times$ circulation time $(\mathrm{h})]$

\section{RT-PCR Quantitation of Messenger RNA Levels}

Total RNA was isolated from the retinas of both diabetic and nondiabetic animals using Trizol reagent (Invitrogen, Carlsbad, CA, USA). Firststrand cDNA was prepared using approximately $5 \mu \mathrm{g}$ of total RNA and an oligo dT primer. RT-PCR was performed using $2 \mu \mathrm{l}$ of first strand cDNA, Ampli-Taq Gold (Applied Biosystems, Foster City, CA, USA) and the appropriate primers (Table 1). Cycling conditions were similar for all primer pairs 
Table 1 Primer pairs for RT-PCR

\begin{tabular}{llc}
\hline Gene & Primer sequence & $\begin{array}{c}\text { Product size } \\
(\mathrm{bp})\end{array}$ \\
\hline MMP-2 & $\begin{array}{l}\text { CCA-CAT-TCT-GGC-CTG-AGC-TCC-C } \\
\text { GAT-TTG-ATG-CTT-CCA-AC-TTC-AC }\end{array}$ & 436 \\
MMP-9 & $\begin{array}{l}\text { CGG-TCG-GTA-TTG-GAA-GTT-CTC-G } \\
\text { GCT-GAA-GCA-AAA-GAG-GAG-CCT-TAG }\end{array}$ & 536 \\
MMP-14 & AAA-GGG-AAC-AAA-TAC-TGG-AA & \\
& ATG-TAG-TTA-GGG-GGA-TGG-AA & 576 \\
GAPDH & $\begin{array}{l}\text { TGT-GAT-GGG-TGT-GAA-CCA-CGA-G } \\
\text { AGA-ATG-GGA-GTT-GCT-GTT-GAA-GTC }\end{array}$ & \\
&
\end{tabular}

and include $94^{\circ} \mathrm{C}$ for 9 min followed by 30 cycles at $94^{\circ} \mathrm{C}$ for $1 \mathrm{~min}, 56-60^{\circ} \mathrm{C}$ for $1 \mathrm{~min}$ and $72^{\circ} \mathrm{C}$ for $1 \mathrm{~min}$. Products were analyzed by $1.2 \%$ agarose gel electrophoresis and ethidium bromide staining to determine the abundance of specific transcripts. Quantitation of band intensity was performed using the image analysis software (Alpha Innotech. San Leandro, CA, USA).

In some cases, real-time RT-PCR was used to confirm the changes seen using conventional RT-PCR. The primers and probes for the real-time RT-PCR were designed using the Primer Express software (Applied Biosystems, Foster City, CA, USA). Amplification and detection was performed using the Gene Amp 5700 system (Applied Biosystems, Foster City, CA, USA). The level of glyceraldehyde-3phosphate dehydrogenase (GAPDH) was used to normalize results. Data were derived using the comparative Ct method of duplicate reactions for five animals for each condition. ${ }^{10}$

\section{Cell Culture}

Experiments were performed using bovine retinal microvessel endothelial cells (BRMVE) (VEC Technologies, Inc., Rensselaer, NY, USA) and ARPE-19, an immortalized human retinal pigment epithelial cell line (ATCC, Manassas, VA, USA). The ARPE-19 cells were maintained in DMEM media supplemented with $10 \%$ fetal bovine serum (FBS), $100 \mathrm{U} / \mathrm{ml}$ penicillin, $100 \mu \mathrm{g} / \mathrm{ml}$ streptomycin. BRMVE cells were grown on fibronectin-coated dishes (Becton Dickinson, Bedford, MA, USA) in MCDB-131 complete media with FBS and antibiotics (VEC Technologies, Inc., Rensselaer, NY, USA). Passages 3-7 were used for transepithelial electrical resistance (TER) experiments and Western blots.

In some experiments, the effect of glucose levels on the production of MMPs by ARPE-19 and endothelial cells was evaluated. Cells were grown in serum-free media containing either $5 \mathrm{mM}$ glucose, $25 \mathrm{mM}$ glucose, or $5 \mathrm{mM}$ glucose $+20 \mathrm{mM}$ mannose for $24 \mathrm{~h}$. The media was removed and fresh serumfree media was added for an additional $24 \mathrm{~h}$. The conditioned media were collected and analyzed by gelatin zymography. ${ }^{6}$ MMP-2 and MMP-9 were visualized as zones of clearing and identified based upon molecular weight and comigration with a standard MMP preparation (HT-1080 conditioned media). The bands were quantitated using the Alpha Innotech Image analysis system. The area of the zones of proteolysis was expressed as an integrated density value and corrected for differences in the amount of protein loaded per lane.

\section{TER of ARPE-19 and BRMVEC}

TER of cell monolayers was determined using a voltmeter and tissue resistance measurement chamber (World Precision Instruments, Sarasota, FL, USA). ARPE-19 and BRMVEC were grown to confluency on 6.5-mm diameter transwell permeable membranes (VWR International Inc., West Chester, PA, USA) and the initial resistance determined. The background resistance was measured prior to each experiment using a transwell membrane without cells. Fully activated human recombinant MMP-2 or MMP-9 $(6 \mu \mathrm{g} / \mathrm{ml})$ was added to the culture media and resistance measurements were taken at 30-min intervals over a 3 -h period. Resistance across the cell layer was determined by subtracting the background resistance from the total resistance and expressed per unit area $\left(\Omega / \mathrm{cm}^{2}\right)$.

\section{Western Blot Analysis}

ARPE-19 or BRMVEC were washed in ice-cold phosphate-buffered saline (PBS) and scraped from the culture dish in $200 \mu \mathrm{l}$ of $0.1 \%$ triton X-100 in $100 \mathrm{mM} \mathrm{PO}$ buffer. The total cellular extract was incubated for $30 \mathrm{~min}$ on ice and the nonsolubilized material was removed by centrifugation. The resulting extract was divided into several equal aliquots. One nontreated aliquot was heated to $95^{\circ} \mathrm{C}$ for $5 \mathrm{~min}$ in sodium dodecyl sulfate (SDS)-sample buffer. Additional aliquots received either purified MMP-2 or MMP-9 $(6 \mu \mathrm{g} / \mathrm{ml})$ with or without $75 \mu \mathrm{M}$ MMP2/9 inhibitor ((2R)-2-[(4-biphenylylsulfonfyl)amino]3-phenylpropionic Acid (Calbiochem, San Diego, CA, USA). These samples were incubated at $37^{\circ} \mathrm{C}$ for $1 \mathrm{~h}$. A final aliquot was incubated at $37^{\circ} \mathrm{C}$ for $1 \mathrm{~h}$ without any MMP added. At the end of the incubation period, SDS sample buffer was added and the samples were loaded onto a $10 \%$ polyacrylamide gel for electrophoresis. Proteins were transferred onto PVDF membrane and blocked with TBS/0.1\% Tween $+1 \%$ dry milk overnight at $4^{\circ} \mathrm{C}$. The membranes were incubated with antibody to either occludin $(2.5 \mu \mathrm{g} / \mathrm{ml})$, or claudin-5 $(1 \mu \mathrm{g} / \mathrm{ml})$ (Zymed Laboratories Inc., San Francisco, CA, USA) for $1 \mathrm{~h}$ at room temperature. The membranes was rinsed three times for $10 \mathrm{~min}$ in TBS/Tween and again blocked for $15 \mathrm{~min}$. The membranes were subsequently incubated with a biotin-labeled antibody for $1 \mathrm{~h}$ at room 
temperature. The membranes were rinsed and blocked for $15 \mathrm{~min}$, incubated for $1 \mathrm{~h}$ at room temperature with an AP-conjugated antibiotin antibody and bands were detected using NBT/BCIP as a substrate for alkaline phosphatase.

\section{Immunofluorescence Microscopy}

Cells were passed onto glass coverslips coated with gelatin and allowed to reach confluence. Cells were incubated in the presence of MMP-9 $(6 \mu \mathrm{g} / \mathrm{ml})$ for either $30 \mathrm{~min}$ (BRMVEC) or $1 \mathrm{~h}$ (ARPE-19). Control cells received no MMP treatment. The cells were fixed in a 3:1 solution of ice-cold methanol/acetic acid for $2 \mathrm{~min}$ and then washed with PBS. Coverslips were blocked with $10 \%$ goat serum and incubated with antioccludin or anticlaudin-5 antibody for $1 \mathrm{~h}$ at room temperature. Coverslips were rinsed three times for $10 \mathrm{~min}$ in TBS/0.1\% Tween-20 and incubated with a fluorescently labeled secondary antibody for $1 \mathrm{~h}$ at room temperature, washed and mounted with Vectashield (Vector Laboratories, Burlingame, CA, USA). Specimens were observed using a fluorescence microscope and images were captured and pseudocolored using the MetaMorph Image Analysis program.

\section{Statistical Methods}

For all quantitative experiments, data from diabetic and nondiabetic samples were compared using a Student's $t$-test using a two-tailed $P$-value with $\alpha$ set at 0.05 .

\section{Results}

\section{Diabetic Rat Model}

Nine animals were used in both the diabetic and control groups. Rats were injected with streptozotocin to induce diabetes and were maintained for 12 weeks with insulin to prevent weight loss and increase long-term survival. The body weights of the nondiabetic animals increased by $109 \%$ in 12 weeks, whereas the increase in the body weights of the diabetic animals was only $13 \%$. During this period, blood glucose levels were found to average 167 and $500 \mathrm{mg} / \mathrm{dl}$ for nondiabetic and diabetic rats, respectively. Diabetes was further confirmed by quantitating the percentage of $\mathrm{GHb}$. Diabetic rats were found to have a 2.74-fold increase in $\mathrm{GHb}$ levels when compared to nondiabetic animals (Table 2).

\section{BRB Permeability Increases in Response to Diabetes}

One eye from each animal was used to quantitate the degree of vascular permeability of the retinal vessels. Evans blue dye was used to determine the
Table 2 Body weight, blood glucose levels (Glc) and GHb levels in diabetic and nondiabetic rats

\begin{tabular}{lccr}
\hline Group & $\begin{array}{c}\text { Body weight } \\
(\mathrm{g})\end{array}$ & $\begin{array}{c}\text { Blood glucose } \\
(\mathrm{mg} / \mathrm{dl})\end{array}$ & $\%$ GHb \\
\hline $\begin{array}{l}\text { Nondiabetic } \\
\text { Diabetic }\end{array}$ & $419 \pm 56$ & $167 \pm 27$ & $6.06 \pm 1.1$ \\
& $226 \pm 65^{*}$ & $500 \pm 64^{*}$ & $16.61 \pm 3.3^{*}$ \\
\hline
\end{tabular}

Data are the mean \pm standard deviation. Rats were made diabetic by intraperitoneal injection of streptozotocin $(60 \mathrm{mg} / \mathrm{kg})$ in $10 \mathrm{mM}$ citrate buffer, pH 4.5. Beginning body weights were $200 \mathrm{~g}$ for both control and diabetic animals. The determination of GHb levels was made at the end of 12 weeks of diabetes. *Significantly different from nondiabetic animals $(P=0.0001)$.

extent of vascular permeability, a technique that effectively measures the movement of albumin from the plasma into the surrounding tissues. Following 12 weeks of diabetes, rats were found to have a nearly two-fold increase in retinal vascular permeability, $2.19 \mu \mathrm{l} / \mathrm{g}$ h compared to nondiabetic rats with $1.16 \mu \mathrm{l} / \mathrm{g}$ h (Figure 1). The differences observed were statistically significant $(P<0.004)$.

\section{Increased Levels of Extracellular Proteinases in the Retinas of Diabetic Animals}

The levels of specific extracellular proteinase messenger RNA (mRNA) were determined in the whole retinas of 12-week diabetic animals and compared to nondiabetic controls. Using conventional semi quantitative RT-PCR, both MMP-2 and MMP-9 mRNA levels were found to be significantly elevated (2.8- and 2.3-fold respectively) in the retina of diabetic animals (Figure 2a and b). Additionally, the membrane type MMP, MMP-14, was elevated 2.5 -fold in the diabetic rat.

Real-time RT-PCR was utilized to confirm the changes seen by conventional RT-PCR. MMP-9 and MMP-14 were found to have a 2.1- and 2.2-fold increase in the amounts of mRNA in diabetic retinas, respectively.

\section{MMP-9 Production is Enhanced in Isolated Cells Exposed to High Concentrations of Glucose}

We next examined whether elevated levels of glucose could induce a change in MMP production in isolated cells. Cells were grown in media containing either $5 \mathrm{mM}$ glucose, $25 \mathrm{mM}$ glucose or $5 \mathrm{mM}$ glucose $+20 \mathrm{mM}$ mannose for $24 \mathrm{~h}$. A significant increase was seen in the production of MMP-9 by both cell types grown in $25 \mathrm{mM}$ glucose compared to the other media (Figure 3). The predominant form of the enzyme was the $92 \mathrm{kDa}$ nonactive proteinase. The absence of active form could be explained by the fact that the factors necessary for activation (ie plasminogen and plasmin) were absent from the cultures when grown in serum-free media. No significant change was seen in the production of 


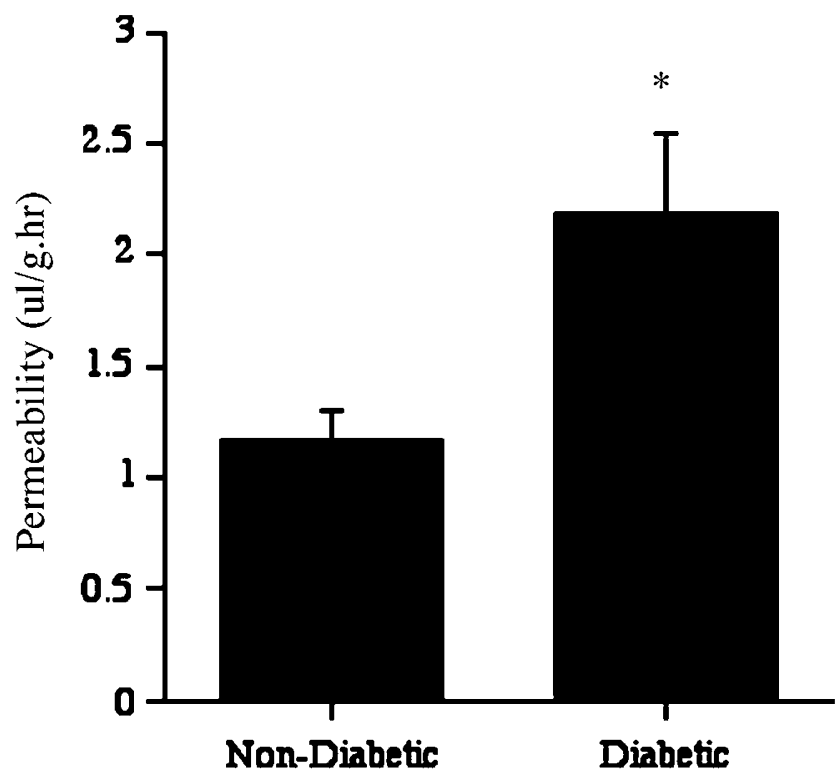

Figure 1 Retinal permeability as determined by the Evans blue dye technique is increased in the rat following 12 weeks of diabetes. The permeability of the retinal vasculature is nearly two-fold higher in diabetic rats $(2.19 \pm 0.2904 \mu \mathrm{l} / \mathrm{g} \mathrm{h})$ as compared to nondiabetic rats $(1.16 \pm 0.1301 \mu \mathrm{l} / \mathrm{gh})$. Values are the mean \pm s.e.m. of $N=9$ animals for each group. * Significantly greater than nondiabetic $(P=0.023)$

MMP-2 by these cells in any of the three growth media (Figure 3).

\section{Purified MMPs Alter Tight Junction Integrity in Cultured Cells}

Initially, ARPE-19 cells were treated with increasing doses of MMP-9 and the TER was measured over a 3$\mathrm{h}$ period. A dose-dependent response was observed, and further experiments were carried out using a concentration of MMP $(6 \mu \mathrm{g} / \mathrm{ml})$ which showed a gradual, rather than a rapid, decrease in the TER (data not shown).

ARPE-19 cells treated with MMP-2 or MMP-9 exhibited a significant decrease in paracellular permeability as determined by TER measurement. The TER decreased significantly from 181 to $36 \Omega$ / $\mathrm{cm}^{2}$ over a 3-h period following MMP-2 treatment and from 181 to $45 \Omega / \mathrm{cm}^{2}$ following treatment with MMP-9 (Figure 4).

Although their initial baseline resistance was significantly lower than that seen in the ARPE-19 cells, the BRMVEC responded to MMP treatment in a similar manner. Cells treated with MMP-2 resulted in a significant decrease in resistance, from 64 to 21 and from 76 to $15 \Omega / \mathrm{cm}^{2}$ when treated with MMP-9 (Figure 5). A Trypan blue exclusion assay was performed to confirm that the addition of MMPs to cell cultures was not toxic. In both cell types, $98 \%$ of the cells were found to be viable following treatment with the MMPs.

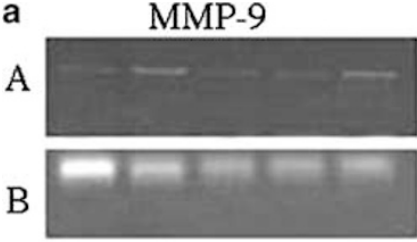

GAPDH

A

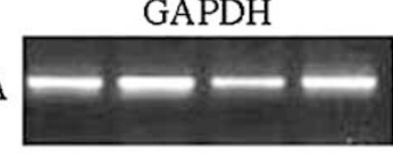

B
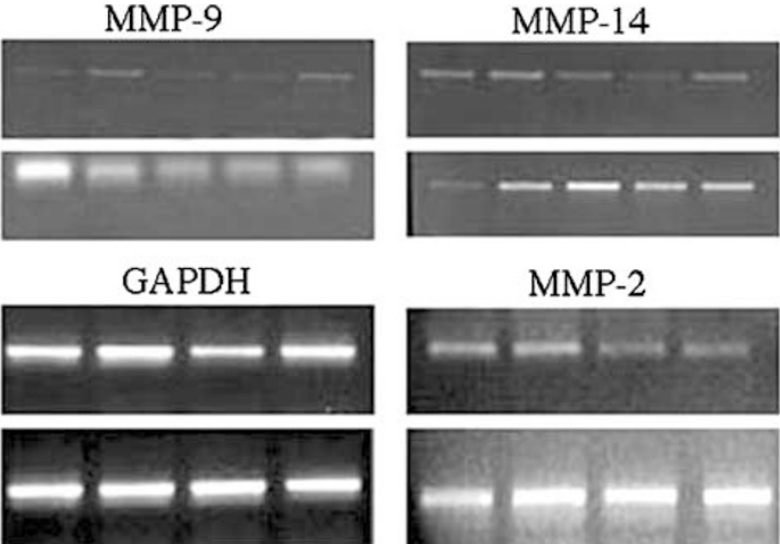

MMP-2
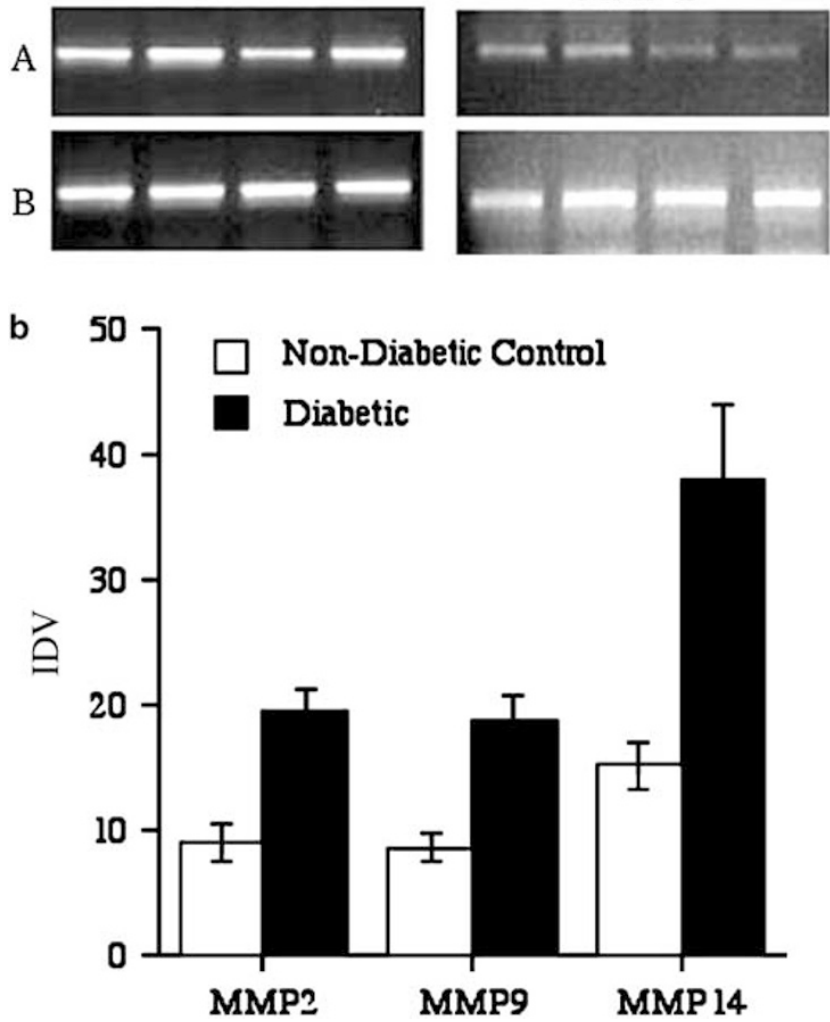

Figure 2 (a) MMPs are upregulated in the diabetic retina. The mRNA levels of specific extracellular proteinases were evaluated in the retina of animals with 12 weeks of diabetes using RT-PCR. Representative agarose gels from nondiabetic (panel A) and diabetic (panel B) animals are shown. Each lane represents an individual animal within each group. The specific gene of interest is indicated. (b) Quantitation of RT-PCR analysis. The level of specific mRNA, corrected for differences in GAPDH levels between samples, is represented graphically. Values are the mean of the integrated density value (IDV) + s.e.m. from four or five nondiabetic and diabetic animals. * Significantly greater than non-diabetic (MMP-2, $P=0.0038$; MMP-9, $P=0.0029$; MMP-14, $P=0.0063)$.

\section{MMP Degradation of Specific Tight Junction Components}

Occludin and claudin-5 proteins were examined by Western blotting of both BRMVEC and ARPE-19 cell extracts following treatment with purified MMP-2 and MMP-9. Occludin was present in both cell types whereas claudin-5 is present only in endothelial cells and was thus examined only in the BRMVEC.

Occludin migrates with a molecular weight of 62-64 kDa. Claudin-5 migrates as a single band of approximately $24 \mathrm{kDa}$. A decrease in band intensity in the Western blot following MMP treatment was 


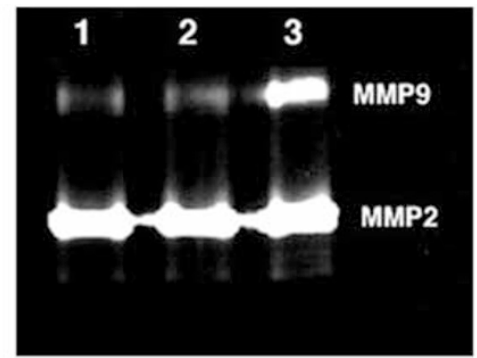

C

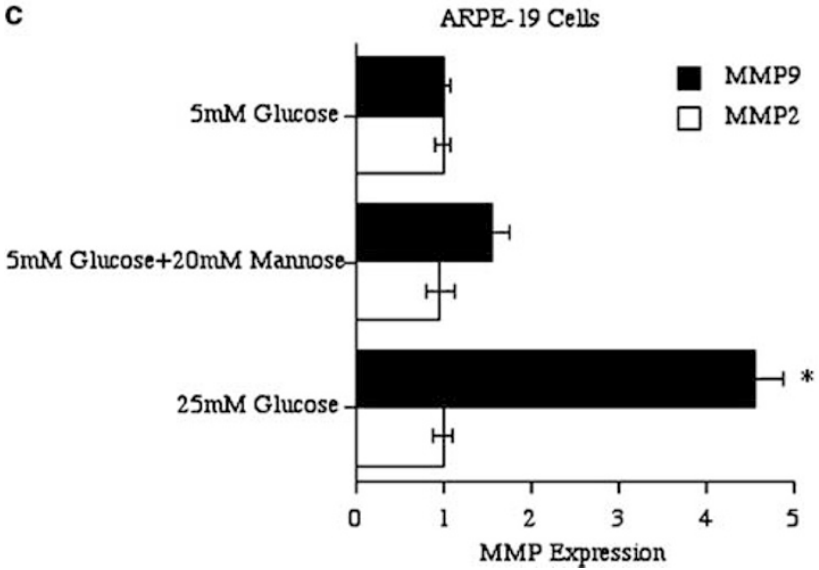

b

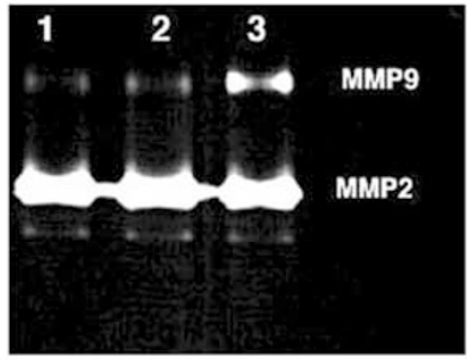

d

BRMVEC

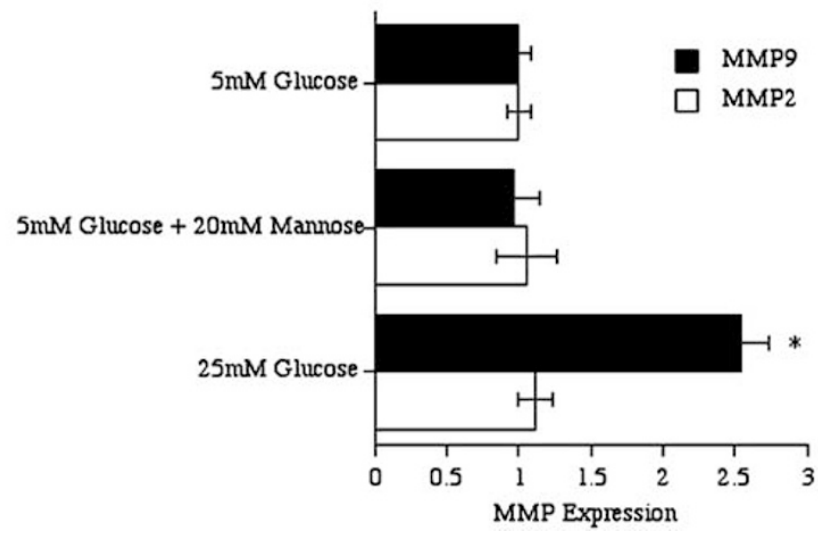

Figure 3 MMP-9 production is increased in ARPE-19 (a and $\mathbf{c}$ ) and bovine retinal endothelial cells (b and d) in response to high glucose stimulation. (a and b) Representative gelatin zymograms of the conditioned media of cells grown for $24 \mathrm{~h}$ in media containing $5 \mathrm{mM}$ glucose (Lane 1), $5 \mathrm{mM}$ glucose $+20 \mathrm{mM}$ mannose (Lane 2), or $25 \mathrm{mM}$ glucose (Lane 3). The positions of MMP-2 and MMP-9 are indicated. Quantitative analysis of MMP-9 and MMP-2 at $24 \mathrm{~h}$ (c and d). Values are the mean of three individual cultures \pm s.e.m. ${ }^{*}$ Significantly greater than $5 \mathrm{mM}$ glucose and $5 \mathrm{mM}$ glucose $+20 \mathrm{mM}$ mannose $(P=0.043)$.

correlated with the proteolytic degradation of the protein. A decrease in the intensity of the occludin bands was seen in both MMP-2- and MMP-9-treated protein extracts, after $1 \mathrm{~h}$ incubation at $37^{\circ} \mathrm{C}$ (Figure 6). Treating the protein extracts with MMP-2 or MMP-9 in the presence of the MMP inhibitor resulted in an attenuation of the MMP- induced disappearance of occludin. MMP-2 and MMP-9 treatment of cell extracts had no effect on claudin5 from the BRMVEC as the intensity of the claudin-5 band was unchanged in response to the treatment.

We next examined the morphological changes which occurred in the BRMVEC and ARPE-19 cells following the addition of MMP-9. Both cell types form a monolayer in culture which became disrupted following the addition of MMP-9 to the cultures (Figures 7a,b and 8a,b). Both cell types exhibited a continuous layer of occludin staining localized to the lateral cell borders (Figures 7c and 8c). After $30 \mathrm{~min}$ (BRMVEC) or $1 \mathrm{~h}$ (ARPE-19) of MMP-9 treatment, the pattern of occludin staining was altered in both cell types (Figures $7 \mathrm{~d}$ and $8 \mathrm{~d}$ ). The BRMVEC appeared to lose the majority of the occludin initially present at the cell borders except where cells maintained contact with one another. A similar response was seen in the ARPE-19 cells, where the occludin became more punctate in appearance and was absent from areas where cells began to visibly separate from one another. The untreated BRMVEC also exhibited a continuous pattern of claudin-5 staining associated with the lateral cell borders (Figure 7e). A slightly different response was seen in the claudin-5 staining pattern following MMP-9 treatment. Claudin-5, like occludin, was lost from cell borders when cells lost contact with one another, but appeared normal in terms of staining intensity in other regions where cells were in contact.

\section{Discussion}

The major findings of this study are: (1) that MMPs are upregulated in the retina in an animal model of early diabetic retinopathy at a time when there is an increase in the BRB permeability, (2) that high levels of glucose cause an increased production of MMP-9 in isolated retinal endothelial cells, (3) that the MMPs effect the function of the transcellular permeability barrier in cultures of ARPE-19 and retinal microvascular endothelial cells, and (4) that MMPs specifically degrade the tight junction protein occludin. Together, these findings suggest that elevated expression of MMPs in the retina of diabetic animals may facilitate an increase in vascular permeability by a mechanism involving proteolytic degradation of occludin or other junctional proteins. 


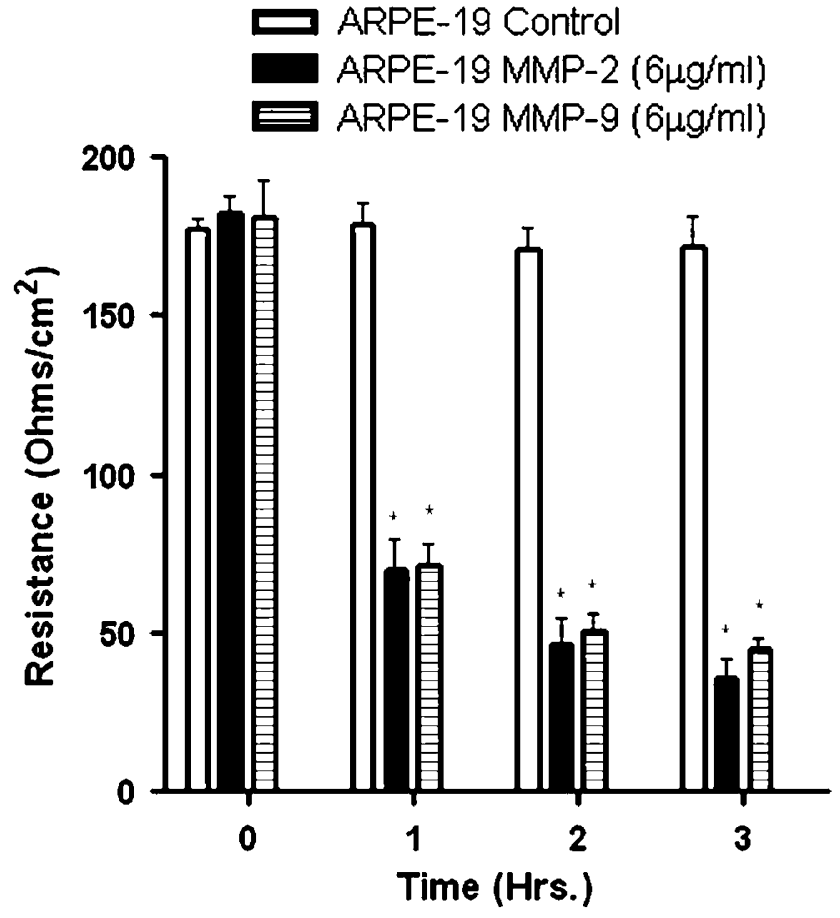

Figure 4 MMP treatment of ARPE-19 cells increases paracellular permeability. Integrity of tight junctions between ARPE-19 cells was determined by TER following treatment with $6 \mu \mathrm{g} / \mathrm{ml} \mathrm{MMP-2}$ or MMP-9. The TER decreased from 182 to $36 \Omega / \mathrm{cm}^{2}$ in $3 \mathrm{~h}$ following MMP-2 treatment and from 181 to $45 \Omega / \mathrm{cm}^{2}$ with MMP9. Control cells maintained a steady baseline resistance throughout the duration of the experiment. Values are the mean \pm s.e.m. for $N=3$ individual wells. *Significantly less than control $(P<0.05)$.

As compared to occludin, the endothelial-specific the tight junction protein claudin-5 did not appear to be susceptible to degradation by MMP-2 or MMP9 under the conditions of these experiments. Although an exact role for occludin in the function of tight junctions has not been fully established, it is postulated that occludin has some role in stabilizing claudin oligomers ${ }^{11}$ as well as regulating the activity of the cytoskeleton with various signaling pathways in the cell. ${ }^{4}$ A recent study has demonstrated that the addition of peptides corresponding to a portion of the occludin extracellular domain caused increased permeability in cells as measured by TER. ${ }^{12}$ This study suggests that disruption of occludin alone is enough to cause a functional change in the tight junctions. In the retina of diabetics, the degradation of occludin by MMPs may therefore disrupt the stability of the tight junction complex between adjacent microvascular endothelial cells leading to leakage and macular edema.

We have reported the elevation of MMP-2, MMP-9 and MMP-14 mRNAs in the retinas of 12-week diabetic rats. Earlier time points were not examined for expression of these proteinases as we noted no significant increase in permeability in the animals prior to 12 weeks using the Evans blue technique. A recent study has reported increased retinal perme-

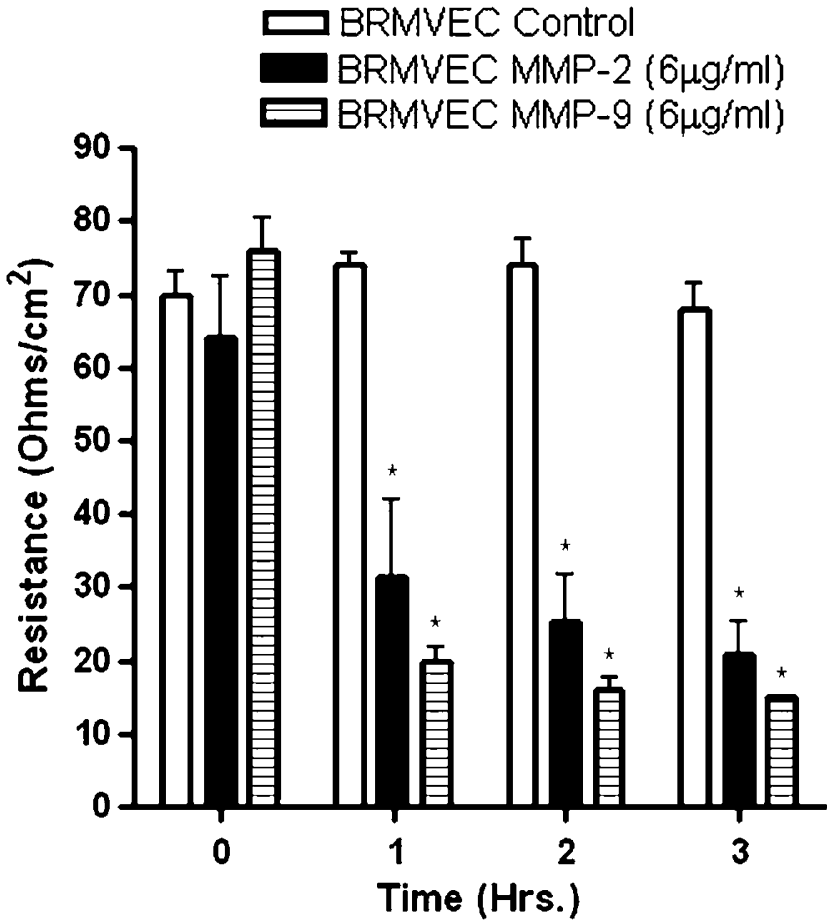

Figure 5 MMP treatment of BRMVEC increases paracellular permeability. Integrity of tight junctions between BRMVEC was determined by TER following treatment with $6 \mu \mathrm{g} / \mathrm{ml}$ MMP-2 or MMP-9. The TER decreased from 64 to $21 \Omega / \mathrm{cm}^{2}$ in $3 \mathrm{~h}$ following MMP-2 treatment and from 74 to $15 \Omega / \mathrm{cm}^{2}$ in $3 \mathrm{~h}$ with MMP-9. Control cells maintained a steady baseline resistance throughout the duration of the experiment. Values are the mean + s.e.m. for $N=3$ individual wells. *Significantly less than control $(P<0.05)$.

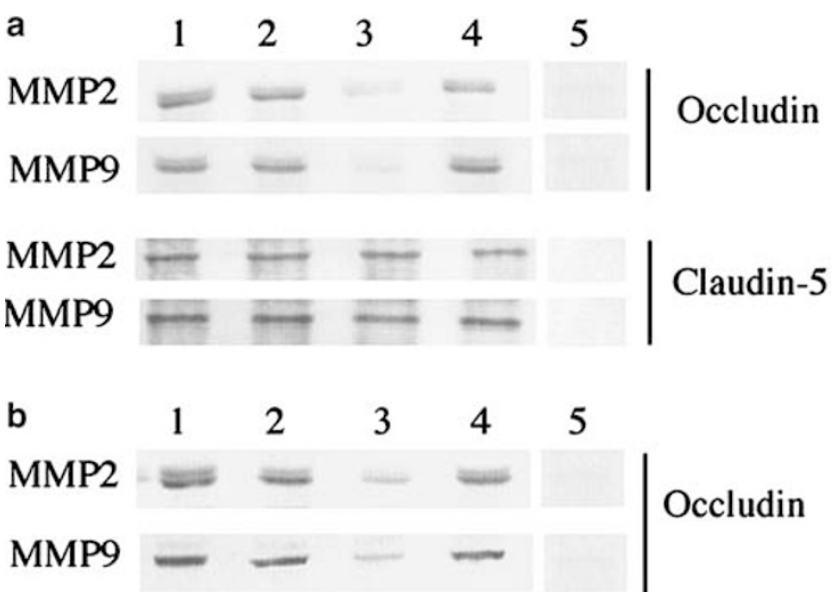

Figure 6 The tight junction proteins occludin and claudin-5 are differentially sensitive to proteolysis by MMPs. Occludin in extracts of BRMVEC (a) or ARPE-19 (b) and claudin-5 present in extracts of BRMVEC (a) were examined via Western blotting following a $1 \mathrm{~h}$ treatment of the extract with MMP-2 or MMP-9 at $37^{\circ} \mathrm{C}$ as indicated. Lane $1=$ no MMP and no incubation. Lane $2=$ no MMP, incubation for $1 \mathrm{~h} 37^{\circ} \mathrm{C}$. Lane $3=\mathrm{MMP}-2$ or MMP-9, $1 \mathrm{~h} 37^{\circ} \mathrm{C}$. Lane $4=$ MMP- 2 or MMP-9, $1 \mathrm{~h} 37^{\circ} \mathrm{C}$ plus MMP2/MMP9 inhibitor. Lane $5=$ no MMP and no incubation, no primary antibody control. Equal amounts of total protein extract were loaded in each lane. Loss of band intensity is indicative of protein degradation. 

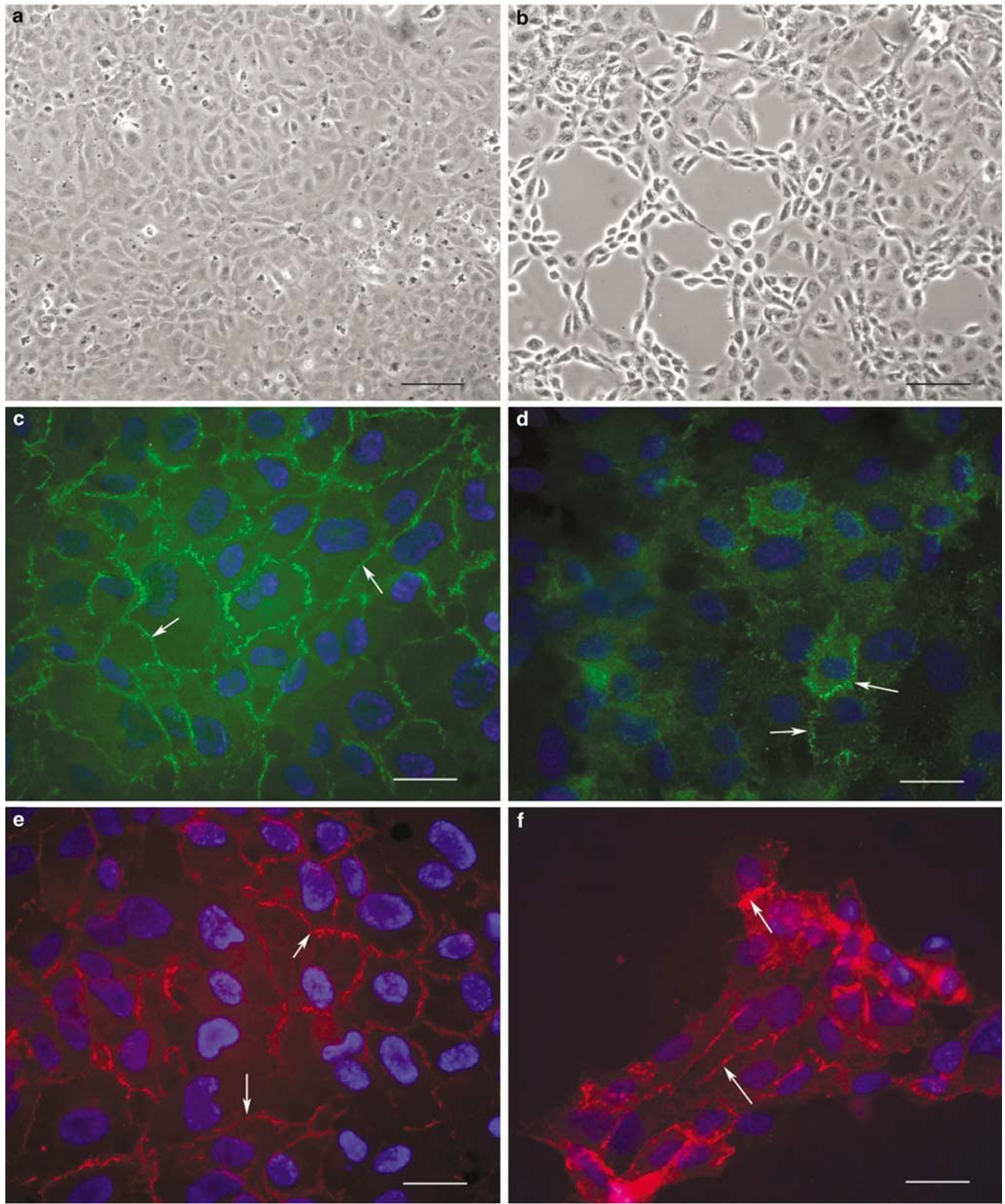

Figure 7 Treatment of BRMVEC with MMP-9 induces a loss of the tight junction protein occludin and retraction of adjacent cell borders. BRMVEC were treated for $30 \mathrm{~min}$ with $6 \mu \mathrm{g} / \mathrm{ml} \mathrm{MMP-9}$ and fixed for occludin and claudin-5 immuostaining. (a) Phase contrast image of untreated cells showing the typical monolayer morphology (bar $=33 \mu \mathrm{m}$ ). (b) Phase contrast image of cells incubated for 30 min with MMP-9 (bar $=33 \mu \mathrm{m}$ ). (c) Untreated cells stained for occludin. Note the continuous staining associated with lateral cell borders (arrows) (bar $=8.3 \mu \mathrm{m}$ ). (d) Cells treated with MMP-9 display loss of occludin at the cell borders except for where cell-cell attachment is maintained (arrows) (bar $=8.3 \mu \mathrm{m}$ ). (e) Untreated cells stained for claudin-5. Claudin-5 localizes to the lateral cell borders (arrows) (bar $=8.3 \mu \mathrm{m}$ ). (f) Cells treated with MMP-9 display loss of claudin-5 at the cell borders except for where cell-cell attachment is maintained (arrows) (bar $=8.3 \mu \mathrm{m})$. 

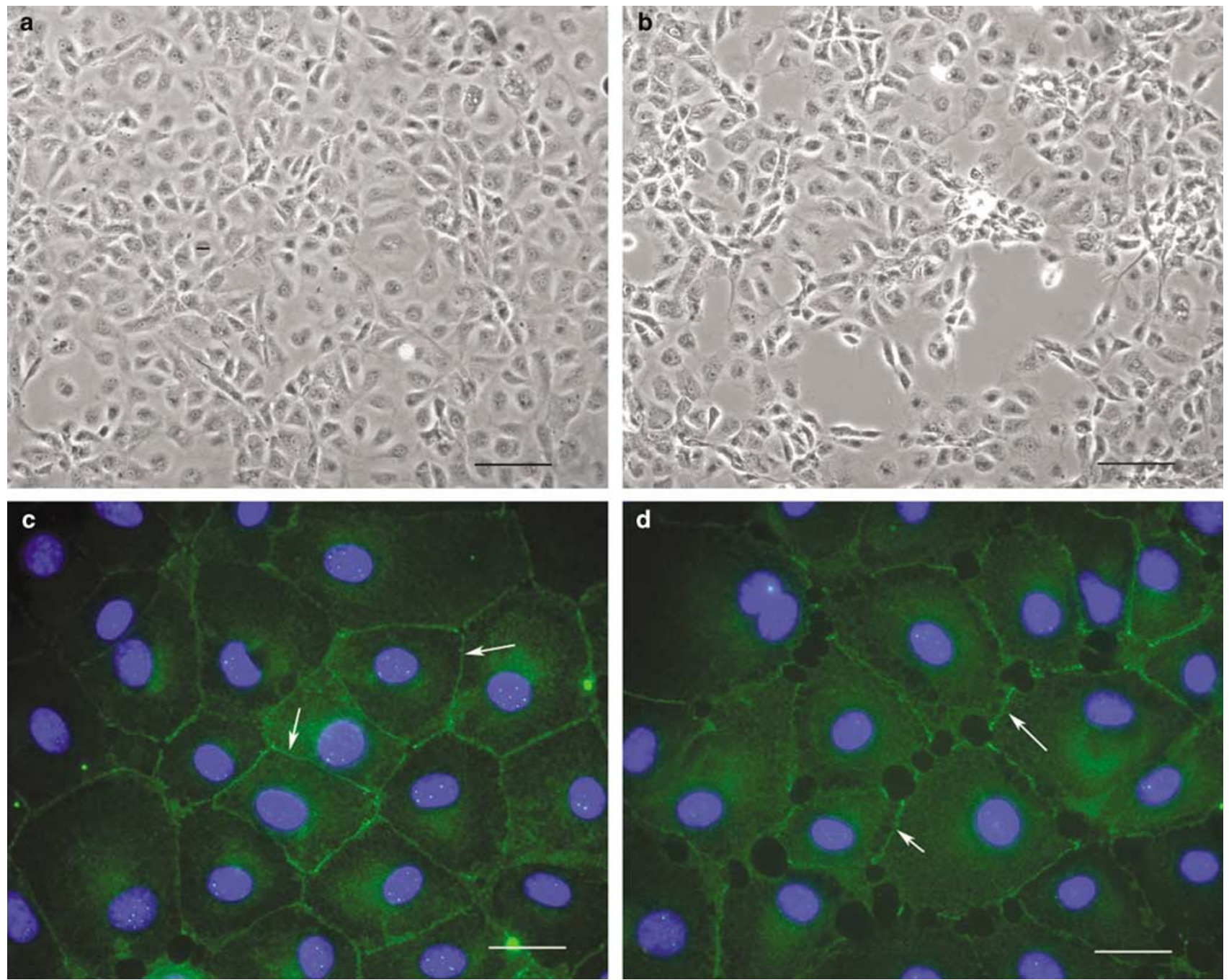

Figure 8 Treatment of ARPE-19 cells with MMP-9 induces a loss of the tight junction protein occludin and retraction of adjacent cell borders. ARPE-19 cells were treated for $1 \mathrm{~h}$ with $6 \mu \mathrm{g} / \mathrm{ml} \mathrm{MMP-9}$ and fixed for occludin immuostaining. (a) Phase contrast image of untreated cells showing the typical monolayer morphology (bar $=33 \mu \mathrm{m}$ ). (b) Phase contrast image of cells incubated for 30 min with MMP-9 (bar $=33 \mu \mathrm{m})$. (c) Untreated cells stained for occludin. Note the continuous staining associated with lateral cell borders (arrows) (bar $=8.3 \mu \mathrm{m}$ ). (d) Cells treated with MMP-9 display a loss of occludin at the cell borders except for where cell-cell attachment is maintained (arrows) (bar $=8.3 \mu \mathrm{m})$.

ability at 2 weeks of diabetes in the rat using AlexaFluor 488-labeled BSA. ${ }^{13}$ This study demonstrates the variability of permeability results that can be obtained depending upon the technique used.

MMPs are secreted as proenzymes that are activated autocatalytically or by other proteases such as uPA and plasmin. The serine proteinase uPA, through its conversion of plasminogen to plasmin, may directly effect the tight junction proteins between adjacent endothelial cells, or may function to activate MMP-2 and MMP-9 resulting in a breakdown of the tight junction protein occludin by these enzymes. A previous study reported on a role for uPA in the regulation of the paracellular permeability pathway in VEGF-treated cultured endothelial cells. ${ }^{14}$ It is unclear whether the elevated levels of uPA were having a direct effect on the cells in this study or whether the effect was via the activation of MMPs which may have been produced as well. Indeed, MMPs and the uPA/uPAR system have been previously demonstrated to overlap and cooperate in other physiological contexts such as wound healing. ${ }^{15}$

The increase of MMPs in diabetic animals may be partly due to the direct effects of hyperglycemia, increased VEGF expression, or the production of other diabetes-related products including reactive oxygen species (ROS) and advanced glycation end products (AGE). Increased endothelial cell expression of MMP-2 and MMP-9 in response to hyperglycemia has previously been reported. ${ }^{16,17}$ In the present study, we confirmed that high levels of glucose resulted in an increased production of MMP-9 in cultured retinal endothelial cells. In addition, the formation of AGE, as a consequence of hyperglycemia, can cause increased expression of 
MMPs through NF- $\kappa$ B upregulation in retinal microvascular endothelium. ${ }^{18} \mathrm{~A}$ previous study reported that cells treated with VEGF demonstrated increased paracellular permeability, as well as upregulation of uPAR levels. ${ }^{14}$ Prolonged hyperglycemia induces increased levels of ROS such as hydrogen peroxide, hydroxyl radicals and super oxide anions. ${ }^{19,20}$ Hyperglycemia and ROS have also been correlated with an elevation of MMP-9 expression and activity that can be attenuated by treatment with antioxidants. ${ }^{17}$ It is apparent that in the development of diabetes proteinase expression may be increased by a variety of biochemical mechanisms.

The proteolytic degradation of tight junction proteins in response to hyperglycemia and increased VEGF levels may be facilitated by the elevated expression of specific extracellular proteinases. To further investigate the role of the MMPs in BRB breakdown, Western blots were used to examine the integrity of occludin and claudin-5 in ARPE19 and BRMVEC extracts treated with MMPs. The addition of MMP-2 or MMP-9 resulted in a loss of occludin band intensity; however, no effects on claudin-5 from BRMVEC were noted. This suggests that specific degradation of a single protein within the tight junction complex may result in an overall breakdown of the barrier as demonstrated by the TER experiments. Although occludin by itself cannot form a functionally tight barrier, it likely plays an important role in organization and stabilization of the tight junction. ${ }^{21-23}$ Its breakdown by MMPs may thus result in an overall disruption of the barrier and increased vascular leakage.

The specificity of MMP degradation of occludin can be partially explained by the fact that MMP-2 cleaves peptide bonds such as Gly-Val, Gly-Leu, Gly-Asn, and Gly-Ser). ${ }^{24}$ Occludin contains two extracellular domains at AA90-135 and AA196243. In the occludin peptide, there are three Gly-Ser residues in the first extracellular domain and two Gly-Ser, one Gly-Val and one Gly-Leu in the second extracellular domain. It is plausible that MMP-2 cleaves occludin at one or more of these sites resulting in alteration of tight junction structure and function. Confirmation of this will require a detailed mapping of the proteolytic site using preparations of purified occludin.

Serum levels of VEGF are significantly increased in individuals with diabetes, and glycemic control and the duration of diabetes influences the extent of this elevation. ${ }^{25-27}$ VEGF has a well-known effect on increasing vascular permeability. VEGF may exert its effects on the BRB through a variety of mechanisms. This growth factor has been shown to alter the expression pattern of specific tight junction proteins in endothelial cells. ${ }^{28,29}$ In addition, studies have demonstrated that increased vascular permeability in experimental diabetes is associated with reduced endothelial occludin content. ${ }^{30}$ VEGF has been shown to cause rapid phosphorylation of occludin, which correlates with an increase in permeability between endothelial cells. ${ }^{31}$ These studies report the proteolytic breakdown of occludin in response to VEGF treatment but did not identify the enzymes involved.

Although this present study focuses on the paracellular molecular flux between the endothelial cells, we cannot rule out the possibility of the transcellular flux that may play a role in increased retinal permeability. The VEGF-induced permeability has been attributed to the formation of vesiculovacuolar organelles (VVOs) in retinal endothelial cells in culture ${ }^{32}$ that are responsible for transcellular transport. It has been suggested that some or all tight junction complexes may function to define the apical vs basolateral environment and formation of VVOs and transcellular transport. ${ }^{33}$

In this study, we present a probable mechanism for the alteration of the BRB by MMPs. We have shown that MMP-2, MMP-9 and MMP-14 are upregulated in the retina from diabetic animals and associated with BRB permeability changes. In addition, MMP-2 and MMP-9 both have the ability to degrade occludin and alter the functional capacity of tight junctions in vitro. Although the present study has not examined a direct role for MMPs in the alteration of occludin in vivo, a previous study has shown reduced endothelial occludin in the retinas of diabetic animals with increased vascular permeability. ${ }^{30}$ Further studies are in progress in this lab-utilizing specific MMP inhibitors in an in vivo model of diabetic retinopathy to correlate occludin content with changes in vascular permeability. A greater understanding of the role of proteases in altering tight junction proteins in diabetic retinopathy will provide future targets for therapeutic intervention. Along these lines, current studies are underway to determine if inhibition of the uPA/uPAR and/or MMP systems in vivo can prevent or reverse the alteration of the BRB and permeability changes seen in the early stages of diabetic retinopathy.

\section{Acknowledgements}

This study was supported by Grant \#RO1 EY1260404 (AD) from the National Institutes of Health.

\section{References}

1 Frank B. Etiologic mechanisms in diabetic retinopathy. In: Ryan SJ (ed). Retina. Mosby: St Louis, MO, 2001, pp 1259-1289.

2 Vinores SA, Derevjanik NL, Ozaki H, et al. Cellular mechanisms of blood-retinal barrier dysfunction in macular edema. Doc Ophthalmol 1997;97:217-228.

3 Dejana E, Spagnuolo R, Bazzoni G. Interendothelial junctions and their role in the control of angiogenesis, vascular permeability and leukocyte transmigration. Thromb Haemost 2001;86:308-315. 
4 Schneeberger EE, Lynch RD. The tight junction: a multifunctional complex. Am J Physiol Cell Physiol 2004;286:C1213-C1228.

5 Furuse M, Fujita K, Hiiragi T, et al. Claudin-1 and -2: novel integral membrane proteins localizing at tight junctions with no sequence similarity to occludin. J Cell Biol 1998;141:1539-1550.

6 Das A, McGuire PG, Eriqat C, et al. Human diabetic neovascular membranes contain high levels of urokinase and metalloproteinase enzymes. Invest Ophthalmol Vis Sci 1999;40:809-813.

7 Das A, McLemore A, Song WS, et al. Retinal neovascularization is suppressed with a matrix metalloproteinase inhibitor. Arch Ophthalmol 1998;117:498-503.

8 Noda K, Ishida S, Inoue $\mathrm{M}$, et al. Production and activation of matrix metalloproteinase-2 in proliferative diabetic retinopathy. Invest Ophthalmol Vis Sci 2003;44:2163-2170.

$9 \mathrm{Xu} \mathrm{Q}$, Qaum T, Adamis AP. Sensitive blood-retinal barrier breakdown quantitation using Evans blue. Invest Ophthalmol Vis Sci 2001;42:789-793.

10 Johnson MR, Wang K, Smith JB, et al. Quantitation of dihydropyrimidine dehydrogenase expression by realtime reverse transcription polymerase chain reaction. Anal Biochem 2000;278:175-184.

11 Sasaki H, Matsui C, Furuse K, et al. Dynamic behavior of paired claudin strands within opposing plasma membranes. Proc Natl Acad Sci USA 2003;100:39713976.

12 Tavelin S, Hashimoto K, Malkinson J, et al. A new principle for tight junction modulation based on occludin peptides. Mol Pharmacol 2003;64:1530-1540.

13 El-Remessy A, Behzadian MA, Abou-Mohamed G, et al. Experimental diabetes causes breakdown of the blood-retinal barrier by a mechanism involving tyrosine nitration and increases in expression of vascular endothelial growth factor and urokinase plasminogen activator receptor. Am J Pathol 2003;162:1995-2004.

14 Behzadian MA, Windsor LJ, Ghaly N, et al. VEGFinduced paracellular permeability in cultured endothelial cells involves urokinase and its receptor. FASEB J 2003;17:752-754.

15 Lund LR, Romer J, Bugge TH, et al. Functional overlap between two classes of matrix-degrading proteases in wound healing. EMBO J 1999;18:4645-4656.

16 Grant MB, Caballero S, Tarnuzzer RW, et al. Matrix metalloproteinase expression in human retinal microvascular cells. Diabetes 1998;47:1311-1317.

17 Uemura S, Matsushita H, Li W, et al. Diabetes mellitus enhances vascular matrix metalloproteinase activity: role of oxidative stress. Circ Res 2001;88:1291-1298.

18 Moore TC, Moore JE, Kaji Y, et al. The role of advanced glycation end products in retinal microvascular leukostasis. Invest Ophthalmol Vis Sci 2003;44:44574464.

19 Spitaler MM, Graier WF. Vascular targets of redox signaling in diabetes mellitus. Diabetologia 2002;45: 476-494.
20 Ellis EA, Guberski DL, Somogyi-Mann M, et al. Increased $\mathrm{H}_{2} \mathrm{O}_{2}$, vascular endothelial growth factor and receptors in the retina of the BBZ/WOR diabetic rat. Free Radic Biol Med 2000;28:91-101.

21 Chen Y-H, Merzdorf DL, Paul DL, et al. $\mathrm{COOH}$ terminus of occludin is required for tight junction barrier function in early Xenopus embryos. J Cell Biol 1997;138:891-899.

22 Balda MS, Whitney JA, Flores C, et al. Functional dissociation of paracellular permeability and transepithelial electrical resistance and disruption of the apical-basolateral intramembrane diffusion barrier by expression of a mutant tight junction membrane protein. J Cell Biol 1996;134:1031-1049.

23 Wong V, Gumbiner BM. A synthetic peptide corresponding to the extracellular domain of occludin perturbs the tight junction permeability barrrier. J Cell Biol 1997;136:399-409.

$24 \mathrm{Yu}$ AE, Murphy AN, Stetler-Stevenson WG. 72-kDa gelatinase (gelatinase A): structure, activation, regulation and substrate specificity. In: Parks WC, Mecham RP (eds). Matrix Metalloproteinases. Academic Press: New York, 1998, pp 85-106.

25 Chiarelli F, Spagnolit A, Basciani F, et al. Vascular endothelial growth factor (VEGF) in children, adolescents and young adults with type 1 diabetes mellitus: relation to glycaemic control and microvascular complications. Diab Med 2000;17:650-656.

26 Murata T, Nakagawa K, Khalil A, et al. The relation between expression of vascular endothelial growth factor and breakdown of the blood-retinal barrier in diabetic rat retinas. Lab Invest 1996;74:819-825.

27 Gilbert RE, Vranes D, Berka JL, et al. Vascular endothelial growth factor and its receptors in control and diabetic rat eyes. Lab Invest 1998;78:1017-1027.

28 Wang W, Dentler WL, Borchardt RT. VEGF increases BMEC monolayer permeability by affecting occludin expression and tight junction assembly. Am J Physiol Heart Circ Physiol 2001;280:H434-H440.

29 Fisher S, Wobben M, Marti HH, et al. Hypoxia-induced hyperpermeability in brain microvessel endothelial cells involves VEGF-mediated changes in the expression of zonula occludens-1. Microvasc Res 2002;63: 70-80.

30 Antonetti DA, Barber AJ, Khin S, et al. Vascular permeability in experimental diabetes is associated with reduced endothelial occluding content. Diabetes 1998;47:1953-1959.

31 Antonetti DA, Barber AJ, Hollinger LA, et al. Vascular endothelial growth factor induces rapid phosphorylation of tight junction proteins occludin and zonula occluden 1. J Biol Chem 1999;274:23463-23467.

32 Antonetti DA, Leith E, Barber AJ, et al. Molecular mechanisms of vascular permeability in diabetic retinopathy. Semin Ophthalmol 1999;14:240-248.

33 Feng Y, Venema VJ, Venema RC, et al. VEGF-induced permeability increase is mediated by caveolae. Invest Ophthalmol Vis Sci 1999;40:157-167. 